\title{
Use of tannins to improve fatty acids profile of meat and milk quality in ruminants: A review
}

\author{
Rodrigo Morales ${ }^{1 *}$, and Emilio M. Ungerfeld ${ }^{2}$
}

\begin{abstract}
This paper reviews how tannins, through their effects on rumen lipid metabolism, can affect the composition of ruminants' meat and milk fat. Tannins are a heterogeneous group of plant secondary compounds known for both beneficial and detrimental effects on animals' digestive physiology. Tannins supplementation of ruminants' diets alters both in vivo and in vitro unsaturated fatty acids biohydrogenation and hence the profile of fatty acids outflowing the rumen, which can influence milk and meat content of beneficial fatty acids such as linolenic acid $(c 9, c 12, c 15-18: 3)$, vaccenic acid $(t 11-18: 1)$ and rumenic acid $(c 9, t 11-18: 2)$, among others. Published information indicates that tannins could inhibit biohydrogenation though affecting ruminal microorganisms. Some studies found increments in linolenic, rumenic and/or vaccenic acids in meat and milk fat using different sources of tannins; however, the effects of tannins supplementation on milk and meat fatty acid profile are not consistent, and there are contradictory results published in the literature. Effects of tannin supplementation on fatty acids biohydrogenation are affected by the chemical type of tannins, the complexity of their interactions with dietary components, and the potential microbial adaptation to tannins. In addition, the duration of the tannins-feeding period may also affect milk and meat fatty acid profile. Characterizing the effects of each specific tannic compound on different biohydrogenation steps and on the microbial species conducting them, as well as the interaction between specific tannin compounds and other dietary components can help to take greater advantage of tannins potential to contribute to improve human health through promoting beneficial fatty acids in ruminants products.
\end{abstract}

Key words: Biohydrogenation, condensed tannins, conjugated linoleic acids, hydrolysable tannins, product quality,

\section{INTRODUCTION}

Tannins are chemically heterogeneous, water-soluble polyphenols synthesized by some trees, shrubs, legumes, herbs, and cereal grains (Patra and Saxena, 2009). Tannins are not involved in plant growth or reproduction (Patra and Saxena, 2010). They are classified into hydrolyzable tannins (HT), with molecular weight between 500 and $3000 \mathrm{~g} \mathrm{~mol}^{-1}$, and condensed tannins (CT) with molecular weight up to $20000 \mathrm{~g} \mathrm{~mol}^{-1}$ (Cieslak et al., 2013). Tannins share an affinity to bind proteins, and to a lesser extent metal ions, amino acids, and carbohydrates in aqueous solution (Makkar, 2003). As such, they can have antimicrobial effects due to their capacity to bind microbial enzymes or cell wall or membrane proteins, or proteins in the substrate, decreasing microbial attachment and digestion.

\footnotetext{
${ }^{1}$ Instituto de Investigaciones Agropecuarias, INIA Remehue, Ruta 5 Norte km 8, P.O. Box 24-0, Osorno, Chile.

*Corresponding author (rmorales@inia.cl).

${ }^{2}$ Instituto de Investigaciones Agropecuarias, INIA Carillanca, P.O. Box 58-D, Temuco, Chile.

Received: 7 October 2014.

Accepted: 26 February 2015.

doi:10.4067/S0718-58392015000200014
}

In the past, tannins were classified as "anti-nutrients" due to the impairment of feed intake and nutrient utilization they can cause; however, their antimicrobial properties have opened the possibility of using them to manipulate ruminal microbial activity in favorable directions, e.g. slow down protein digestion, increase microbial protein synthesis, decrease methanogenesis, modify fatty acids biohydrogenation and prevent bloat (Makkar, 2003; Waghorn and McNabb, 2003; Patra and Saxena, 2011). Tannins can also have post-ruminal benefits e.g. parasite control (Waghorn and McNabb, 2003). The objective of this review was to specifically focus on how tannins, through their effects on rumen fatty acids metabolism, affect the composition of ruminants' meat and milk fat.

\section{Fatty acids biohydrogenation in the rumen}

Due to the process of biohydrogenation of unsaturated fatty acids conducted by ruminal microorganisms, ruminant fats are more saturated than non-ruminants' (Jenkins et al., 2008). Rumen microbiota metabolizes most dietary PUFAs by complex processes of enzymatic and chemical isomerizations and reductions leading to intermediates such as conjugated linoleic acids (CLA) and other fatty acids, with stearic acid (18:0) as the final product (Figure 1). Many of the intermediates outflow the rumen and are absorbed and further desaturated, elongated, or chain- 


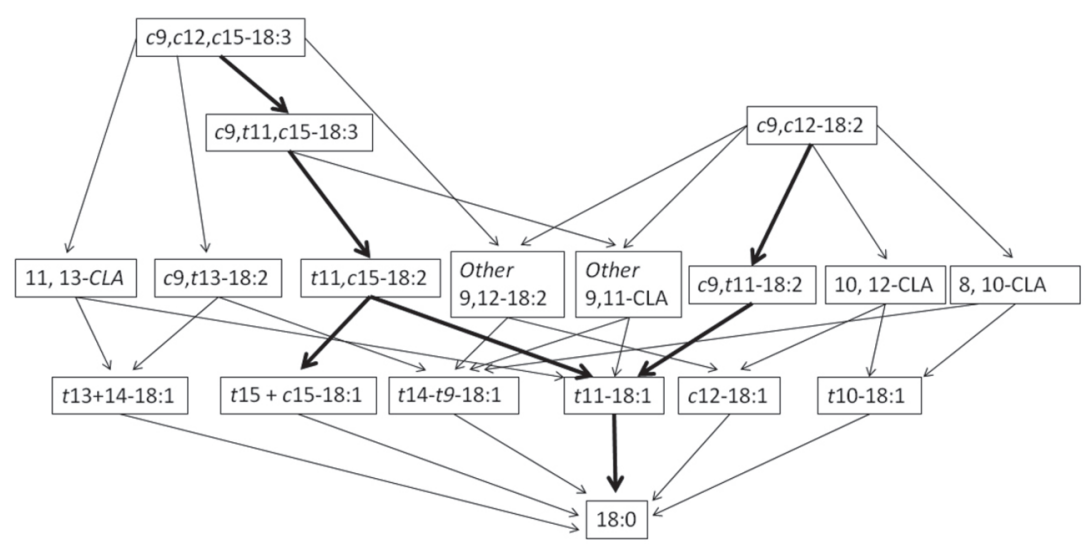

Figure 1. Biohydrogenation pathways in the rumen. Linoleic acid: $c 9, c 12-18: 2$; Linolenic acid:c9,c12,c15-18:3. Adapted from Chilliard et al. (2007).

shortened in the animal's tissues (Wallace et al., 2007; Shingfield et al., 2010). The competition between the rates of biohydrogenation and passage, along with the forage to concentrate ratio, dictates the profile of fatty acids that outflows the rumen (Aldai et al., 2013).

The fatty acids present in forages, cereals, and oil seeds are mainly linoleic (LA; $c 9, c 12-18: 2)$ and linolenic (LNA; $c 9, c 12, c 15-18: 3$ ), whereas some oil seeds are rich in monounsaturated fatty acids (MUFA; mainly oleic acid $c 9-18: 1)$. Linoleic acid is partly converted to CLA in the rumen, mainly rumenic acid (RA; $c 9, t 11-18: 2$ ), which is then converted to vaccenic acid (VA; $t 11-18: 1$ ) and finally stearic acid (18:0, Figure 1). Linolenic acid is metabolized in a similar way (Figure 1), although because there are three double bonds to be reduced, the pathway is more complex (Jenkins et al., 2008) and LNA metabolism results in the production of a series of intermediates (Figure 1) (Chilliard et al., 2007). Oleic acid can be converted to several trans-18:1 position isomers; conversion rates of the different monounsaturated position isomers to stearic acid is variable (Jenkins et al., 2008). Direct biohydrogenation of oleic acid to stearic acid has not been discarded. Another route of oleic acid ruminal metabolism (which does not involve biohydrogenation) is hydration of oleic acid to 10-hydroxystearic acid followed by its oxidation to 10-ketostearic acid (Jenkins et al., 2008).

Consumption of saturated fats in meat and dairy products from ruminants is associated with increased incidence of coronary diseases (Jenkins et al., 2008). The World Health Organization recommends reducing consumption of 12:0, 14:0, 16:0, and trans-fatty acids (FAO/WHO, 2010). Depending on the type of diet fed to a ruminant, different types of fatty acids are deposited in meat and milk. For example, 14:0, 16:0 and $t 10$ 18:1 accumulate in concentrate-finished beef (Leheska et al., 2008; Aldai et al., 2011); these fatty acids have been associated with increased coronary heart disease incidence (FAO/WHO, 2010). In contrast, grazing ruminants produce milk and meat products with a more desirable fatty acid composition for human health (Kalač and Samková, 2010; Morales et al., 2012). Rumenic acid and its precursor VA have been found to accumulate in forage-finished ruminants and despite to be trans-fatty acids, their consumption has been linked to a number of potential health benefits (Dilzer and Park, 2012). In this sense, there is much interest in improving the nutritional value of ruminants' products to human health by increasing $n-3$ polyunsaturated fatty acids (PUFA), RA, and VA, and decreasing the content of saturated fatty acids and transfatty acids detrimental to human health.

The rumenic acid is a rumen biohydrogenation intermediate that contributes to prevention of cancer and arteriosclerosis, improves immune response, lowers plasma low-density/high-density lipoprotein ratio, and promotes lean tissue deposition (Jenkins et al., 2008; Dilzer and Park, 2012). Vaccenic acid is also of much interest because it can be converted to RA through endogenous desaturation in the host animal's tissues (Jenkins et al., 2008; Or-Rashid et al., 2009). In addition, some studies reported that VA has hypolipidemic (Jacome-Sosa et al., 2010) and anticarcinogenic effects in humans (Miller et al., 2003). These authors hypothesized that these properties are due to the conversion of VA to $\mathrm{RA}$ in non-ruminants through $\Delta 9$-desaturase. Turpeinen et al. (2002) estimated the rate of conversion of VA to RA to be in the range from 5\% to $12 \%$ in rodents and $19 \%$ to $30 \%$ in humans.

Manipulating ruminal biohydrogenation is of much interest to improve the nutritive value of ruminants's products. If the target is elevating RA content in meat or milk, one would attempt inhibiting the last step of biohydrogenation without affecting the conversion of LA and LNA to RA and VA. Rumenic acid reduction to VA needs not be inhibited, because VA would still contribute to RA formation in the animal's tissues through $\Delta 9$ desaturase (Grinarii et al., 2000). In fact, up to $90 \%$ of RA present in meat and milk is of endogenous origin, 
synthesized from VA (Piperova et al., 2002). Therefore the best strategy to increase RA content in meat or milk would be enhancing VA formation in the rumen and its uptake in the duodenum (Vasta and Luciano, 2011).

On the other hand, if the target is elevating ruminants' fat content of polyunsaturated fatty acids, in particular $n-3$ fatty acids, one should attempt to inhibit lipolysis and early biohydrogenation steps (Khiaosa-Ard et al., 2009). The level of $n-3$ fatty acids in milk of grazing animals depends on their concentration in the diet, and is affected by forages botanical composition, phenological stage, and leafiness and conservation method (Cabiddu et al., 2010), as well as biohydrogenation. For example, leaves of Castanea sativa Mill. incubated in vitro inhibited biohydrogenation of LA and LNA in comparison with 17 other plants (Jayanegara et al., 2012). Because the biohydrogenation process has several steps, it is important to study how different dietary interventions affect each of them, in order to understand the likely consequences on the profile of long chain fatty acids exiting the rumen.

Biohydrogenation is affected by factors such as $\mathrm{pH}$, and the amount and type of substrate (Martin and Jenkins, 2002). Consumption of fish and algae oils can also inhibit biohydrogenation and increase ruminal outflow of VA (Boeckaert et al., 2007; Or-Rashid et al., 2009). Other nutritional strategies to enhance the content of beneficial fatty acids in ruminant products through the manipulation of rumen lipolysis and biohydrogenation are grazing grasses high in LNA, feeding vegetable oils or oilseeds, or protected fat (Lourenço et al., 2010). Different fatty acids differ in their effect on different microorganisms that may or may not be involved in lipolysis and different biohydrogenation steps; hence, different oils will have different effect on the rumen microbial community and amount of each fatty acid exiting the rumen (Lourenço et al., 2010). Polyunsaturated fatty acids are more toxic to biohydrogenating bacteria than di- or monoenoic fatty acids, thus oils containing polyunsaturated fatty acids have a greater effect on ruminal biohydrogenation than those containing linoleic and oleic acid (Lourenço et al., 2010). High forage diets decrease the negative effects of unsaturated fatty acids on biohydrogenation (Lourenço et al., 2010).

Plant secondary compounds can also influence biohydrogenation. Plant lipases are important in biohydrogenation with grazed and conserved forages. Polyphenol oxidases can reduce quinones to phenols, which can then bind to lipases and inhibit lipolysis (Cabiddu et al., 2010). There was a negative association between total phenols and LNA biohydrogenation (Cabiddu et al., 2010). Effects of essential oils on biohydrogenation vary depending on the compound, concentration, basal diet, $\mathrm{pH}$, and adaptation period. The effects of saponins have also varied depending on the compound used (Lourenço et al., 2010).

\section{Chemistry and biological effects of tannins}

Hydrolyzable tannins are derivatives of gallic acid or its dimer hexahydroxydiphenic acid, partially or totally esterified to a polyhydroxylated core. Condensed tannins are classified in two types: proanthocyanidines are composed of anthocyanidins and/or catechin flavan-3ol monomers, and leucoanthocyanidines are dimmers of flavan-3, 4-diolflavonoids (Patra and Saxena, 2009; 2010). Chemical composition of tannins, as well as their concentration, depends on plant species, the part of the plant, and environmental factors such as climate, soil, topography (Patra and Saxena, 2011), and phenological stage (Berard et al., 2011).

Biological properties are greatly dependent on their chemical structure (Makkar, 2003; Patra and Saxena, 2009; 2010), which can be even more important than concentration (Waghorn and McNabb, 2003). Lower molecular weight tannins have greater reactivity with proteins (Patra and Saxena, 2011). Furthermore, tannins can interact with other plants secondary compounds, such as saponins (Makkar, 2003). This issue is further complicated by the fact that several analytical methods exist, and the different results that they yield have biological implications. Results of butanol- $\mathrm{HCl}$ extractions of free, protein-bound and fiber-bound tannins are influenced by available binding sites in proteins. Higher protein concentration, for example, decreases the content of free tannins. The drying technique (oven $v s$. freeze drying) also influences the results obtained in the analysis (Waghorn and McNabb, 2003). Other methods to analyze complex tannin mixtures separating catechin, epicatechin, gallocatechin, and epigallocatechin flavan-3ol units by HPLC are reported (Stringano et al., 2011).

In the rumen, tannins bind with plant proteins, reducing dietary proteins availability to the ruminal microbiota and the host animal. Polyethylene glycol (PEG) binds to tannins more effectively than proteins do and inactivates them (Makkar, 2003). Supplementation with PEG has then been used as a control treatment in research on tannins effects on animal nutrition to neutralize their effects. Comparing the same tannin-containing feed with and without PEG allows evaluating the effects of tannins on the same base diet (Waghorn et al., 1998; Waghorn, 2008).

\section{Effects of tannins on fatty acids biohydrogenation in the rumen}

Tannins can have an effect on ruminal fatty acids biohydrogenation. Quebracho (Schinopsis quebrachocolorado (Schltdl.) F.A. Barkley \& T. Mey.) tannins were shown to inhibit LNA disappearance in vitro, i.e. an early step of biohydrogenation (Kronberg et al., 2007). In another study, supplementation with tannins from carob (Ceratonia siliqua L.) pulp, acacia (Acacia cyanophylla Lind1.) leaves or quebracho in ruminal batch cultures resulted in accumulation of VA and total trans-18:1 fatty 
acids and a decrease in stearic acid at the highest level of tannins addition, without effect on RA, and no differences among tannin sources. This could be interpreted as tannins inhibiting the last reduction step of trans-18 fatty acids to stearic acid without affecting earlier steps. Effects of tannin supplementation on linoleic acid isomerase did not suggest direct inhibition of this enzyme, but of the microorganisms possessing it (Vasta et al., 2009a). Because CLA formation is faster than trans-18:1 reduction to stearic acid, these authors speculated that tannins could have inhibited CLA production in shorter incubations. Their speculations is supported by another study where an initial observed decrease in the content of RA in solidassociated bacteria caused by the addition of chestnut or quebracho tannin extracts was followed by a 2- to 3.4fold increase relative to the control later in the incubation (Buccioni et al., 2011). Interestingly, hydrolyzable chestnut tannins induced an earlier accumulation of RA than quebracho CT. Both types of tannins resulted in less stearic acid in solid-associated bacteria, confirming the inhibition of the last step of biohydrogenation (Buccioni et al., 2011).

In contrast, tannins, and in particular quebracho CT extract, resulted in lower RA in liquid-associated bacteria (Buccioni et al., 2011). It should be noted, however, that the largest proportion of microbial biomass in the rumen are solid-associated microorganisms ( $\mathrm{Yu}$ and Forster, 2005).

Milk from cows grazing at higher elevation has been reported to contain more LNA compared to the lowlands, which has been attributed to the presence of plant secondary compounds in alpine plants that could inhibit biohydrogenation. The association between alpine plants tannin content and LNA biohydrogenation was studied by incubating 18 different alpine plants that could be involved in elevated LNA content in milk (Jayanegara et al., 2012). Chestnut leaves, which are rich in HT, inhibited LA and LNA biohydrogenation, and lowered stearic acid production, but did not affect RA; VA was numerically higher with chestnut leaves in comparison to the rest of the plants incubated (Jayanegara et al., 2012). It appears then that, in that experiment, chestnut mostly inhibited early biohydrogenation steps. Overall, there were negative associations between HT content of the plants and LA and LNA disappearance and stearic acid (18:0) appearance, and a positive association with VA appearance. There was also a weaker positive association between HT and RA appearance. These associations were clearly caused by chestnut leaves, which had the highest content of HT (Jayanegara et al., 2012). Similar results were obtained in a previous study with tannin-containing tropical plants, with total tannins associating negatively to disappearance of LA, LNA, and oleic acid ( $c 9-18: 1)$, and appearance of stearic acid, and positively to appearance of RA but not VA (Jayanegara et al., 2011). In that study, CT explained disappearance of oleic acid and appearance of RA, whereas HT explained the disappearance of LA, LNA, and oleic acid (Jayanegara et al., 2011). In another study, in vitro biohydrogenation rate of five plant species and a grass-clover mixture was compared using inocula from cows fed a total mixed ration, or herb or ryegrass silages (Petersen and Jensen, 2014). Surprisingly, birdsfoot trefoil (Lotus corniculatus L.), a legume with a high content of $\mathrm{CT}$, resulted in the highest relative rate of disappearance of LNA and LA in comparison with other species that have low or do not contain CT. There was an interaction between substrate and ruminal fluid source for LNA disappearance, which was slower for the alfalfa (Medicago sativa L.) substrate with the grass silage inoculum.

In an another interesting experiment, Khiaosa-ard et al. (2011) studied the effect of the source of ruminal fluid (animal adapted to grazing alpine plants or lowlands) on the incubation of three substrates differing in tannin contents: ryegrass (Lolium perenne L.) hay, an alpine grass-maize mixture silage and alpine pasture hay. There were no interactions between substrate and ruminal fluid source. Linolenic acid tended to disappear slightly less with alpine hay, and LA disappeared less with alpine and ryegrass hays. Rumenic acid tended to accumulate more, and VA accumulated more, with ruminal fluid adapted to alpine pasture. There were no effects on stearic acid appearance. Responses induced by ruminal fluid source were greater than those caused by the type of substrate (Khiaosa-ard et al., 2011).

In agreement with in vitro works, feeding quebracho tannins to lambs resulted in accumulation of VA and RA in ruminal fluid, although disappearance of LA and LNA was unaffected. Supplementation with quebracho tannins increased numbers of Butyrivibrio fibrisolvens, which is involved in RA formation, and decreased B. proteoclasticus, which reduces RA to stearic acid. Changes observed in microbial species agreed with changes in fatty acids concentration (Vasta et al., 2010). Tannins did not affect linoleic acid isomerase activity (Vasta et al., 2010).

\section{Effects of tannins on milk fatty acids profile}

The effects of tannin supplementation on milk production and fatty acid composition have been variable and are summarized in Table 1. In contrast to biohydrogenation results with in vitro cultures, milk fatty acid profile was not affected when dairy cows were fed $150 \mathrm{~g} \mathrm{~d}^{-1}$ of quebracho condensed tannin extract (Benchaar and Chouinard, 2009). Similar results were obtained by Kronberg et al. (2007), who did not find effect of tannins on the profile of fatty acids circulating in plasma of steers.

Abbeddou et al. (2011) compared a dairy sheep diet including lentil (Lens culinaris Medik.) straw, which is rich in $\mathrm{CT}$, and olive (Olea europaea L.) leaves, rich in HT, to a control diet or to three other diets containing local feeds and by-products (Atriplex leaves, olive cake, 
Table 1. Effects of dietary tannins on ruminant milk production and fatty acids composition.

\begin{tabular}{|c|c|c|c|c|c|}
\hline Reference & Species & Tannin source & $\begin{array}{l}\text { Dosage and } \\
\text { tannin fraction }\end{array}$ & $\begin{array}{l}\text { Duration of } \\
\text { treatment }(d)\end{array}$ & Effects \\
\hline Benchaar and Chouinard (2009) & Bovine & Quebracho (Schinopsis quebracho-colorado) & $\begin{array}{l}150 \mathrm{~g} \mathrm{~d}^{-1} \mathrm{DM} \\
70 \% \mathrm{CT}\end{array}$ & $\begin{array}{l}\text { 28-d periods }(4 \times 4 \\
\text { Latin Square) }\end{array}$ & $\begin{array}{l}\text { No effects in milk fatty } \\
\text { acids profile }\end{array}$ \\
\hline Cabiddu et al. (2009) & Ovine & $\begin{array}{l}\text { Sulla (grazing) } \\
\text { (Hedysarum coronarium) }\end{array}$ & $\begin{array}{l}2.50 \% \text { to } 2.74 \% \text { DM } \\
\text { CT }\end{array}$ & 56 & $\begin{array}{l}\uparrow \text { LA, LNA and milk fat } \\
\text { content } \\
\downarrow \text { RA, VA, } t 10-18: 1 \text { and } \\
\text { milk urea content }\end{array}$ \\
\hline \multirow[t]{2}{*}{ Abbeddou et al. (2011) } & Ovine & Lentil (Lens culinaris) straw & $\begin{array}{l}0.84 \% \text { DM } \\
74 \% \text { hydrolyzable }\end{array}$ & 50 & $\begin{array}{l}\downarrow \text { LA, LNA, oleic }(c 9- \\
18: 1) \text { and stearic }(18: 0) \\
\text { acids and milk fat content } \\
\uparrow \text { RA }\end{array}$ \\
\hline & & Olive (Olea europaea) leaves & $\begin{array}{l}1.12 \% \text { DM } \\
94 \% \text { hydrolyzable }\end{array}$ & 50 & $\begin{array}{l}\downarrow \text { LA, LNA, } c 9-18: 1 \text { and } \\
18: 0 \text {. } \\
\downarrow \text { energy-corrected milk } \\
\text { yield } \\
\uparrow \text { RA and VA }\end{array}$ \\
\hline Dschaak et al. (2011) & Bovine & Quebracho (S.balansae) & $3 \%$ DM CT & $\begin{array}{l}\text { 21-d periods }(4 \times 4 \\
\text { Latin Square) }\end{array}$ & $\begin{array}{l}\downarrow \text { Milk urea content } \\
\uparrow \text { LNA and total trans- } \\
\text { C18:1 }\end{array}$ \\
\hline Kälber et al. (2011) & Bovine & Buckwheat (Fagopyrum esculentum) & $\begin{array}{l}1.8 \% \text { DM } \\
82 \% \text { hydrolyzable }\end{array}$ & 25 & $\begin{array}{l}\uparrow \mathrm{LA} \text { and LNA } \\
\downarrow t 10-18: 1+\mathrm{VA}\end{array}$ \\
\hline Toral et al. (2011) & Ovine & $\begin{array}{l}\text { 1:1 Red quebracho (S. quebracho- } \\
\text { colorado):chestnut (Castanea sativa) }\end{array}$ & $\begin{array}{l}1 \% \text { DM } \\
50 \% \text { hydrolyzable }\end{array}$ & 28 & $\begin{array}{l}\text { No effects on milk fatty } \\
\text { acids profile }\end{array}$ \\
\hline Kälber et al. (2013) & Bovine & Buckwheat silage & $\begin{array}{l}0.73 \% \text { DM } \\
87 \% \text { hydrolyzable }\end{array}$ & 15 & $\uparrow$ LA and total PUFA \\
\hline Toral et al. (2013) & Ovine & Red quebracho (S. quebracho-colorado) & $2 \% \mathrm{DM} \mathrm{CT}$ & 28 & $\begin{array}{l}\text { No effects on milk fatty } \\
\text { acids profile }\end{array}$ \\
\hline Aprianita et al. (2014) & Bovine & Acacia mearnsii extract & $400 \mathrm{~g} \mathrm{~d}^{-1} \mathrm{CT}$ & $\begin{array}{l}\text { 21-d periods }(4 \times 4 \\
\text { Latin Square) }\end{array}$ & $\begin{array}{l}\text { No effects on milk fatty } \\
\text { acids profile }\end{array}$ \\
\hline
\end{tabular}

CT: Condensed tannins, DM: dry matter, LA: linoleic acid, LNA: linoleic acid, RA: rumenic acid $c 9, t 11-18: 2$ fatty acid, VA: vaccenic acid $t 11-18: 1$ fatty acid, PUFA: polyunsaturated fatty acids.

or tomato (Solanum lycopersicum L.) pomace). Inclusion of lentil straw or Atriplex leaves in the diet, and especially of olive leaves, resulted in higher LA in milk fat; however, recovery of dietary LNA in milk was lesser with lentil straw or olive leaves compared to the control diet; therefore, higher milk fat content of LNA with olive leaves was a consequence of higher LNA content of this feed and not of changes in ruminal biohydrogenation. Inclusion of both lentil straw and olive leaves increased RA and total CLA in milk fat, and olive leaves increased VA and decreased stearic acid (Abbeddou et al., 2011). Greater content of LNA in milk was found when supplementing two diets with different forage to concentrate ratio with $3 \% \mathrm{DM}$ quebracho CT. There were no effects of quebracho tannin supplementation on RA, VA, LA, or stearic acid, although the tannins treatment had higher total trans-18:1 fatty acids concentration (Dschaak et al., 2011).

Tannin-containing dicotyledonous catch crops such as berseem clover (Trifolium alexandrinum L.), buckwheat (Fagopyrum esculentum Moench), and phacelia (Phacelia tanacetifolia Benth.) as well as chicory (Cichorium intybus L.) have been evaluated for their effects on cows' milk fatty acids composition. Buckwheat, followed by chicory, had the greatest content of total and CT. Buckwheat resulted in the greatest recovery of dietary LNA in milk, and recovery of LA was greater than in the ryegrass control (Kälber et al., 2011). At the same time, the diet including buckwheat resulted in less RA and VA $+t 10-18: 1$ in milk fat, compared to berseem clover and the ryegrass control, respectively, and higher stearic acid compared to berseem clover and phacelia (Kälber et al., 2011). It appears then that the inhibition of early steps of biohydrogenation by tannins in buckwheat resulted in lower biohydrogenation intermediates in milk, but CT in buckwheat apparently did not inhibit the last step of biohydrogenation to stearic acid.

Cows fed ensiled buckwheat had a lower intake of LNA than those fed chicory or ryegrass silage, with no difference in LA; transfer of LNA to milk fat was higher with ensiled buckwheat than with ensiled chicory or ryegrass. Milk fat of cows fed buckwheat tended to have more RA and stearic acid, and had more VA. Ensiling caused substantial losses of polyphenols (Kälber et al., 2013).

Supplementation of a sheep diet with a 1:1 condensed:hydrolyzable tannins mixture from quebracho and chestnut origin at $1 \%$ DM basis had no effect on LA, LNA, VA, RA, or stearic acid content in milk fat (Toral et al., 2011). A later study by the same group evaluated a higher dose of quebracho tannins supplement (2\% DM). There were no effects on LA and LNA, or RA or stearic acid content in milk fat, although tannin supplementation tended to result in more VA (Toral et al., 2013). In a recent study, supplementation of cows with Acacia mearnsii De Wild. extract $\left(400 \mathrm{~g} \mathrm{~d}^{-1}\right)$ alone or in combination with cottonseed oil, did not affect fat content and fatty acid profile in milk (Aprianita et al., 2014).

We conducted a preliminary quantitative analysis by regressing milk fat content of LNA, RA, VA, and stearic acid against feed content of CT (DM basis) across 32 
treatment means from nine experiments (Benchaar and Chouinard, 2009; Cabiddu et al., 2009; Abbeddou et al., 2011; Dschaak et al., 2011; Kälber et al., 2011; Toral et al., 2011; 2013; Kälber et al., 2013; Aprianita et al., 2014). We included in the model the experiment as a random effect and its interaction with CT content. The interaction was removed if declared non-significant (variance ratio $<1$ ):

Response $=$ intercept + experiment $+\mathrm{CT}+$ interaction + residual

Treatments including PEG supplementation were considered to be tannin-free, i.e. tannin content was declared to be equal to $0 \% \mathrm{DM}$.

Linolenic acid content in milk fat did not overall associate with CT $(P=0.31)$, except in the study by Cabiddu et al. (2009), in which dosing with PEG decreased LNA in milk fat of sheep grazing sulla $(P=0.024$; Figure $2)$. Milk fat content of RA and VA $(P>0.99)$ and stearic acid $(P=0.93)$ was not associated with feed CT content. In the Cabiddu et al. (2009) study, inactivating sulla tannins with PEG resulted in less LA and LNA in milk fat, in agreement with in vitro and in vivo results on the effects of tannins on biohydrogenation, but, in contrast, the PEG treatment had more RA and VA, without differences in stearic acid. In addition, in the PEG treatment lower $t 10$ 18:1 concentration was also observed (Cabiddu et al., 2009). Because the effect of PEG on LNA disappearance was greater than on LA, PEG supplementation resulted in an increase in the $n-6: n-3$ ratio (Cabiddu et al., 2009).

We also examined for possible interactions between CT content and species and concentrate percentage in the dietary DM on milk fat content of LNA, RA, VA and stearic acid by substituting species or percentage of concentrate in the diet DM for the random effect of the experiment, as follows:

Response $=$ intercept $+\mathrm{CT}+($ species or \% concentrate $)+$ interaction + residual

Whereas there were no interactions on stearic acid, RA or VA, there was a CT by species interaction on LNA $(P$

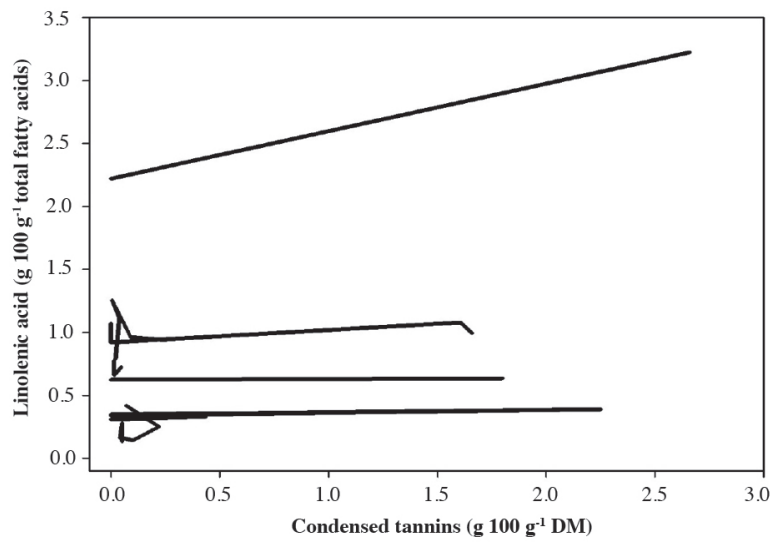

Figure 2. Relationship between condensed tannins content in the diet and milk fat content of alpha-linolenic acid. The Cabiddu et al. (2009) study corresponds to the experiment with the highest alpha-linolenic acid concentration, both in the control and the tannin-inactivated treatment with PEG.
$=0.003$ ), with CT supplementation not affecting milk fat content of LNA in cows, but increasing it in sheep. Also, there was a negative interaction between CT content and the percentage of concentrate on LNA content in milk fat $(P<0.001)$. We are interested, although cautious, about these interactions, for they could be masking experiment effects caused by other factors, such as CT variation in chemical composition. Furthermore, content of CT was determined using different analytical methods, and in some studies the analytical method used was unreported. Dschaak et al. (2011) is the only study we are aware of that examined the interaction between supplementation with CT and the percentage of concentrate in the diet in a controlled experiment, and did not find an interaction between CT and concentrate level on the content of LNA, RA, VA, or stearic acid in milk fat.

\section{Effects of tannins on meat fat fatty acid profile}

Most published studies on the effects of tannin supplementation on meat fatty acid profile were conducted with lambs (Table 2). Different authors have been hypothesized that tannin-rich feeds could reduce or inhibit biohydrogenation of VA to stearic acid, resulting in the accumulation of VA (Priolo and Vasta, 2007; Patra and Saxena, 2011). However, lambs grazing CTcontaining sulla increased LNA content in intramuscular fat (IMF) in longissimus dorsi muscle without affecting RA or VA. Addition of PEG to the sulla diet reduced LNA concentration, evidencing inhibition of early biohydrogenation steps by sulla CT (Priolo et al., 2005). Similarly, feeding lambs a diet supplemented with $2.7 \%$ DM CT from carob reduced the accumulation of RA and VA in IMF of $l$. dorsi muscle (Vasta et al., 2007). Because LA and LNA were also lower in the tanninssupplemented diet, tannins supplementation might have induced alternative biohydrogenation pathways through other 18:1 and 18:2 isomers, although few of these intermediates were reported.

Later work by the same group found that supplementation of fresh forage- or high concentrate-fed lambs diets with quebracho tannins at 4\% DM increased total PUFA and decreased total saturated fatty acids in IMF of $l$. dorsi muscle (Vasta et al., 2009b). Lambs fed with tannins and high concentrate had the highest concentration of t10-18:1 and total trans-18:1 in the IMF, plasma and ruminal fluid. Even though LNA in ruminal fluid was not affected by tannin supplementation, it increased in plasma and tended to increase in muscle. Decrease in stearic acid in ruminal fluid of concentratefed animals supplemented with tannins agreed with a corresponding decrease in stearic acid in muscle, whereas plasma level of stearic acid was not affected by tannins supplementation. Tannins-supplemented animals also had more VA and RA in ruminal fluid. Similarly, Whitney et al. (2011) observed a linear increase in RA and a linear decrease in stearic acid in IMF of $l$. dorsi muscle of 
Table 2. Effects of tannins supplementation on ruminant meat quality.

\begin{tabular}{|c|c|c|c|c|c|}
\hline Reference & Species & Tannin source & $\begin{array}{l}\text { Dosage and } \\
\text { tannin fraction }\end{array}$ & $\begin{array}{l}\text { Duration of } \\
\text { treatment }(d)\end{array}$ & Effects \\
\hline Priolo et al. (2005) & Ovine & $\begin{array}{l}\text { Fresh sulla } \\
\text { (Hedysarum coronarium) }\end{array}$ & $\begin{array}{l}1.8 \% \text { DM CT } \\
\text { (leucocymidin } \\
\text { equivalents) }\end{array}$ & 63 & $\uparrow$ LNA \\
\hline Vasta et al. (2007) & Ovine & $\begin{array}{l}\text { Carob pulp } \\
(\text { Ceratonia siliqua })\end{array}$ & $\begin{array}{l}2.7 \% \text { DM CT } \\
\text { (leucocymidin } \\
\text { equivalents) }\end{array}$ & 45 & $\begin{array}{l}\downarrow \text { RA and VA } \\
\downarrow n-3 \text { FA }\end{array}$ \\
\hline Larraín et al. (2008) & Bovine & High-tannin-sorghum (Sorghum bicolor) & $1.7 \%-3.5 \%$ DM CT & $103-123$ & $\begin{array}{l}\text { No effect in muscle FA } \\
\text { composition }\end{array}$ \\
\hline Vasta et al. (2009b; 2009c) & Ovine & $\begin{array}{l}\text { Quebracho tannins extract } \\
\text { S. quebracho-colorado } \\
\left(456 \mathrm{~g} \mathrm{~kg}^{-1} \mathrm{DM}\right)\end{array}$ & $4.0 \% \mathrm{DM} \mathrm{CT}$ & 60 & $\begin{array}{l}\uparrow t 10-18: 1 \text { and total } \\
\text { trans-18:1 in concentrate } \\
+\mathrm{CT} \text { diet } \\
\uparrow \mathrm{PUFA} \\
\downarrow \mathrm{SFA} \\
\uparrow \mathrm{BH} \text { in concentrate diets }\end{array}$ \\
\hline Jerónimo et al. (2010) & Ovine & $\begin{array}{l}\text { GSE } \\
\text { CL leaves }\end{array}$ & $\begin{array}{l}1.3 \%-1.4 \% \mathrm{DM} \mathrm{CT} \\
2.1 \% \mathrm{DM} \mathrm{CT}\end{array}$ & 42 & $\begin{array}{l}\text { No effect in FA } \\
\text { abomasums digestion and } \\
\text { muscle FA composition }\end{array}$ \\
\hline Staerfl et al. (2011) & Bovine & Acacia mearnsii extract & $14.1 \%$ DM CT & $260-283$ & $\downarrow$ RA \\
\hline Whitney et al. (2011) & Ovine & $\begin{array}{l}\text { Redberry (Juniperus pinchotii) juniper } \\
\text { leaves }\end{array}$ & $\begin{array}{l}\text { Period 1: } 3.1 \%-4.4 \% \\
\text { DM CT } \\
\text { Period 2: } 0.4 \%-2.3 \% \\
\text { DM CT }\end{array}$ & $\begin{array}{l}86(\text { period } 1=28 \\
\text { period } 2=58)\end{array}$ & $\begin{array}{l}\uparrow \mathrm{SFA} \\
\uparrow \mathrm{RA} \\
\uparrow \Delta \text {-9 Desaturase index }\end{array}$ \\
\hline Rana et al. (2012) & Caprine & Terminalia chebula extract & $0.6 \%-1.8 \%$ DM CT & 90 & $\begin{array}{l}\uparrow \text { MUFA, VA, RA and } \\
n \text {-3 FA } \\
\downarrow \text { SFA and } t 9-18: 1 \\
\uparrow \Delta \text {-9 Desaturase index }\end{array}$ \\
\hline Brogna et al. (2014) & Ovine & Aspidosperma quebracho extract & $8 \% \mathrm{DM} \mathrm{CT}$ & 64 & $\begin{array}{l}\text { No effect on muscle FA } \\
\text { composition }\end{array}$ \\
\hline Willems et al. (2014) & Ovine & $\begin{array}{l}\text { Alpine pasture highly biodiverse herbaceous- } \\
\text { shrub type }(0.9: 0.1)\end{array}$ & $\begin{array}{l}0.3 \% \text { DM CT } \\
1.3 \% \text { DM HT }\end{array}$ & 63 & $\begin{array}{l}\uparrow \text { LA, LNA and PUFA } \\
\downarrow \text { Oleic }(c 9-18: 1), \text { RA and } \\
\text { MUFA }\end{array}$ \\
\hline Francisco et al. (2015) & Ovine & Leaves and soft stems of CL & $2.5 \%-16.3 \%$ DM CT & 42 & $\begin{array}{l}\uparrow \text { Other trans-18:1 and } \\
\text { trans-MUFA in the } \\
\text { highest dosage. } \\
\text { No effect on RA and VA }\end{array}$ \\
\hline Whitney and Smith (2015) & Ovine & Redberry juniper branches with leaves & $\begin{array}{l}\text { Period 1: } 0.1 \%-2.3 \% \\
\text { DM CT } \\
\text { Period 2: } 0.3 \%-1.5 \% \\
\text { DM CT }\end{array}$ & $\begin{array}{l}91(\text { period } 1=35 \\
\text { period } 2=56)\end{array}$ & $\begin{array}{l}\uparrow t 10-18: 1 \text { and Total } \\
\text { trans-18:1 } \\
\text { No effect on RA and VA }\end{array}$ \\
\hline
\end{tabular}

BH: Biohydrogenation, CL: Cistus ladanifer L., CT: condensed tannins, DM: dry matter; FA: fatty acids, GSE: grape (Vitis vinifera L.) seed extract, HT: hydrolyzable tannins, LA: linoleic acid, LNA: linoleic acid, MUFA: monounsaturated fatty acids, PUFA: polyunsaturated fatty acids, RA: rumenic acid $c 9, t 11-$ 18:2 fatty acid; SFA: saturated fatty acids, VA: vaccenic acid $t 11-18: 1$ fatty acid.

lambs as the percentage of redberry juniper (Juniperus pinchotii Sudw.) increased in the diet. On the other hand, Whitney and Smith (2015) observed that the inclusion of increasing amounts of juniper (from 5\% to $36 \% \mathrm{DM}$ ) in the diet also increased detrimental fatty acids $t 10-18: 1$ and total trans-18:1 in adipose tissue. No effects on RA and VA were reported.

Jerónimo et al. $(2010 ; 2012)$ reported that supplementation with Cistus ladanifer L. (2.5\%-3.0\% CT in dietary DM) or grape (Vitis vinifera L.) seed extract (2.0\%-2.5\% CT in dietary DM) did not affect RA and VA in IMF. Conversely, Francisco et al. (2015) compared three levels of $C$. ladanifer $(0.3 \%-1.6 \%$ DM of CT). The highest level increased trans-18:1 and trans-MUFA in IMF. Brogna et al. (2014) found no effects of tannins (Aspidosperma quebracho-blanco Schltdl. extract 8\% DM $\mathrm{CT}$ ) on the fatty acid profile of lamb. Supplementation of a kids' diet with a CT extract of Terminalia chebula Retz. resulted in an increase in mono- and polyunsaturated fatty acids, and decreased saturated fatty acids and $t 9-18: 1$ in IMF. Supplementation with tannins increased LA and LNA in ruminal fluid, but not in plasma or muscle. In contrast, more VA and RA and less stearic acid in ruminal fluid translated in corresponding changes in plasma and muscle (Rana et al., 2012).

The same as milk fat, grazing alpine vegetation can also alter meat fatty acid profile. Willems et al. (2014) reported that, even though a lowland pasture contained greater LA and LNA than three different alpine pastures, the IMF of lambs that grazed alpine pasture highest in tannins had the highest LA and LNA concentration. The levels of LA and LNA in body tissues were positively associated with the contents of phenolic compounds in the vegetation but not with vegetation fatty acid content, evidencing the importance of phenolic compounds to rumen biohydrogenation. Rumenic acid in IMF was lower when lambs grazed alpine pastures, suggesting that plant secondary compounds in alpine plants could inhibit early biohydrogenation steps of LA and LNA.

Condensed tannins may indirectly regulate the $\Delta 9$ desaturase expression in tissues through changes induced in the profile of fatty acids absorbed (Vasta et al., 2009c). In this respect, $\Delta 9$-desaturase activity was increased by $47 \%$ to $58 \%$ by CT supplementation, resulting in an 
enhancement of total CLA content in muscle (Whitney et al., 2011; Rana et al., 2012).

There is scarce information on the effect of tannins on the fatty acid profile in beef. Larraín et al. (2009) reported that a diet high in sorghum hybrid (Sorghum bicolor [L.] Moench), with $1.7 \%$ to $3.5 \%$ CT (DM basis) did not affect the fatty acid composition of muscle. Similarly, Staerfl et al. (2011) did not find an effect of supplementation with a tannin extract from Acacia mearnsii at 3.0\% DM on the fatty acid profile of perirenal fat of bulls.

The same as with milk fat composition, a similar regression analysis for the response of fatty acids in meat fat to tannins supplementation was conducted. For the meat fatty acids analysis, we used content of total tannins as regressor rather than CT so as to maximize the number of treatment means (48 treatment means in 12 experiments). Total tannins content negatively associated with stearic acid in meat fat in all experiments $(P=$ 0.045 ; Figure 3$)$, and did not associate with LNA ( $P=$ $0.90)$, RA $(P=0.64)$ or VA $(P=0.56)$. The decrease in stearic acid without accumulation of intermediates such as RA and VA suggests the induction of other pathways of biohydrogenation by tannin supplementation. Unfortunately, the hypothesis of tannins supplementation promoting biohydrogenation pathways other than RA and VA could not be quantitatively examined in a metaanalysis due to the scarcity of reported results on other 18:1 and 18:2 biohydrogenation intermediates.

There were no interactions between tannins supplementation and concentrate percentage in the diet DM on LNA $(P=0.91)$, RA $(P=0.23)$, VA $(P=$ $0.97)$ or stearic acid $(P=0.42)$. Likewise, there were no interactions between tannins supplementation and concentrate percentage in the diet DM on $\operatorname{LNA}(P=0.67)$, RA $(P=0.28)$, VA $(P=0.71)$ or stearic acid $(P=0.31)$.

Tannins have a potential to be used for manipulating ruminal biohydrogenation and fatty acid composition of meat and milk, but how close are we to control their effects so as to effectively manipulate milk and meat fatty

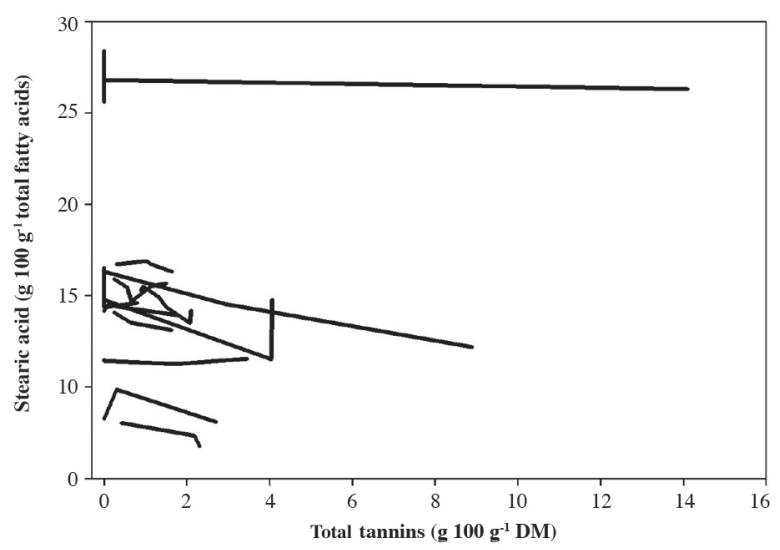

Figure 3. Relationship between total tannins content in the diet and meat fat content of stearic acid. acids profile? At the moment, and due to complex factors already discussed such as tannins chemical variability, interaction with other dietary compounds and microbial adaptation (Makkar, 2003; Waghorn, 2008; Patra and Saxena, 2009), it seems difficult to consistently predict the effects of tannin supplementation on animal products. Furthermore, tannins effects on fatty acid composition of meat and milk should not be considered in isolation, as tannin supplementation exerts various effects on the animal's physiology such as digestion, palatability, performance, toxicity and resistance against parasites. From an analytical viewpoint, characterizing the fatty acid profile of meat and milk has also demonstrated to be challenging because of the large number of fatty acids isomers present (more than 400 according to Aldai et al., 2013). In addition, all possible geometric and positional changes isomers that may occur by tannins effect in the ruminant products should be studied carefully.

\section{CONCLUSIONS}

Changes in the fatty acid profile in meat and milk obtained with tannin supplementation have been variable and unpredictable in terms of $n-3$ polyunsaturated fatty acids (mainly linolenic acid), rumenic acid, vaccenic acid and trans-18:1. Supplementing tannins to in vitro ruminal fluid incubations has also produced variable results regarding which biohydrogenation steps were most affected. A more complete characterization of the effects of the different chemical forms of tannins on the most important ruminal microbial species involved in the process of biohydrogenation, and how this can be affected by the diet and the ruminal environment seems to be necessary to advance knowledge in the area.

\section{LITERATURE CITED}

Abbeddou, S., B. Rischkowsky, E.K. Richter, H.D. Hess, and M. Kreuzer. 2011. Modification of milk fatty acid composition by feeding forages and agro-industrial byproducts from dry areas to Awassi sheep. Journal of Dairy Science 94:4657-4667.

Aldai, N., M.E.R. Dugan, J.K.G. Kramer, A. Martínez, O. LópezCampos, A.R. Mantecón, et al. 2011. Length of concentrate finishing affects the fatty acid composition of grass-fed and genetically lean beef: an emphasis on trans-18:1 and conjugated linoleic acid profiles. Animal 5:1643-1652.

Aldai, N., M. de Renobales, L.J.R. Barron, and J.K.G. Kramer. 2013. What are the trans fatty acids issues in foods after discontinuation of industrially produced trans fats? Ruminant products, vegetable oils, and synthetic supplements. European Journal of Lipid Science and Technology 115:1378-1401

Aprianita, A., O.N. Donkor, P.J. Moate, S.R.O. Williams, M.J. Auldist, J.S. Greenwood, et al. 2014. Effects of dietary cottonseed oil and tannin supplements on protein and fatty acid composition of bovine milk. Journal Dairy Research 81:183-192.

Benchaar, C., and P.Y. Chouinard. 2009. Assessment of the potential of cinnamaldehyde, condensed tannins, and saponins to modify milk fatty acid composition of dairy cows. Journal of Dairy Science 92:3392-3396. 
Berard,N.C.,Y.Wang, K.M. Wittenberg, D.O. Krause, B.E.Coulman, T.A. McAllister, et al. 2011. Condensed tannin concentrations found in vegetative and mature forage legumes grown in western Canada. Canadian Journal of Plant Science 91:669-675.

Boeckaert, C., B. Vlaeminck, J. Mestdagh, and V. Fievez. 2007. In vitro examination of DHA-edible micro algae. 1. Effect on rumen lipolysis and biohydrogenation of linoleic and linolenic acids. Animal Feed Science and Technology 136:63-79.

Brogna, D.M.R., R. Tansawat, D. Cornforth, R. Ward, M. Bella, G. Luciano, et al. 2014. The quality of meat from sheep treated with tannin- and saponin-based remedies as a natural strategy for parasite control. Meat Science 96:744-749.

Buccioni, A., S. Minieri, S. Rapaccini, M. Antongiovanni, and M. Mele. 2011. Effect of chestnut and quebracho tannins on fatty acid profile in rumen liquid- and solid-associated bacteria: An in vitro study. Animal 5:1521-1530.

Cabiddu, A., G. Molle, M. Decandia, S. Spada, M. Fiori, G. Piredda, et al. 2009. Responses to condensed tannins of flowering sulla (Hedysarum coronarium L.) grazed by dairy sheep. Part 2: Effects on milk fatty acid profile. Livestock Science 123:230-240.

Cabiddu, A., L. Salis, J.K.S. Tweed, G. Molle, M. Decandia, and M.R.F. Lee. 2010. The influence of plant polyphenols on lipolysis and biohydrogenation in dried forages at different phenological stages: in vitro study. Journal of the Science of Food and Agriculture 90:829-835.

Chilliard, Y., F. Glasser, A. Ferlay, L. Bernard, J. Rouel, and M. Doreau. 2007. Diet, rumen biohydrogenation and nutritional quality of cow and goat milk fat. European Journal of Lipid Science and Technology 109:828-855.

Cieslak, A., M. Szumacher-Strabel, A. Stochmal, and W. Oleszek. 2013. Plant components with specific activities against rumen methanogens. Animal 7:253-265.

Dilzer, A., and Y. Park. 2012. Implication of conjugated linoleic acid (CLA) in human health. Critical Reviews in Food Science and Nutrition 52:488-513.

Dschaak, C.M., C.M. Williams, M.S. Holt, J.-S. Eun, A.J. Young, and B.R. Min. 2011. Effects of supplementing condensed tannin extract on intake, digestion, ruminal fermentation, and milk production of lactating dairy cows. Journal of Dairy Science 94:2508-2519.

FAO/WHO. 2010. Fats and fatty acids in human nutrition report of an expert consultation. Food and Agriculture Organization of the United Nations and the World Health Organization. FAO Food Nutrition Papers 91:1-175.

Francisco, A., M.T. Dentinho, S.P. Alves, F. Fernandes, S. Sengo, E. Jerónimo, et al. 2015. Growth performance, carcass and meat quality of lambs supplemented with increasing levels of a tanniferous bush (Cistus ladanifer L.) and vegetable oils. Meat Science 100:275-282.

Grinarii, J.M., B.A. Corl, S.H. Lacy, P.Y.Chouinard, K.V.V. Nurmela, and D.E. Bauman. 2000. Conjugated linoleic acid is synthesized endogenously in lactating dairy cows by $\Delta 9$-desaturase. Journal of Nutrition 130:2285-2291.

Jacome-Sosa, M.M., J. Lu, Y. Wang, M.R. Ruth, D.C. Wright, M.J. Reaney, et al. Proctor. 2010. Increased hypolipidemic benefits of cis-9, trans-11 conjugated linoleic acid in combination with trans-11 vaccenic acid in a rodent model of the metabolic syndrome, the JCR:LA-cp rat. Nutrition \& Metabolism 7:60.

Jayanegara, A., M. Kreuzer, and F. Leiber. 2012. Ruminal disappearance of polyunsaturated fatty acids and appearance of biohydrogenation products when incubating linseed oil with alpine forage plant species in vitro. Livestock Science 147:104-112.

Jayanegara, A., M. Kreuzer, E. Wina, and F. Leiber. 2011. Significance of phenolic compounds in tropical forages for the ruminal bypass of polyunsaturated fatty acids and the appearance of biohydrogenation intermediates as examined in vitro. Animal Production Science 51:1127-1136.
Jenkins, T.C., R.J. Wallace, P.J. Moate, and E.E. Mosley. 2008. Board-invited review: Recent advances in biohydrogenation of unsaturated fatty acids within the rumen microbial ecosystem. Journal of Animal Science 86:397-412.

Jerónimo, E., C.M.M. Alfaia, S.P. Alves, M.T.P. Dentinho, J.A.M. Prates, V. Vasta, et al. 2012. Effect of dietary grape seed extract and Cistus ladanifer L. in combination with vegetable oil supplementation on lamb meat quality. Meat Science 92:841-847.

Jerónimo, E., S.P. Alves, M.T.P. Dentinho, S.V. Martins, J.A.M. Prates, V. Vasta, et al. 2010. Effect of grape seed extract, Cistus ladanifer L., and vegetable oil supplementation on fatty acid composition of abomasal digesta and intramuscular fat of lambs. Journal of Agricultural and Food Chemistry 58:10710-10721.

Kalač, P., and E. Samková. 2010. The effects of feeding various forages on fatty acid composition of bovine milk fat: A review. Czech Journal Animal Science 55:521-537.

Kälber, T., J.S. Meier, M. Kreuzer, and F. Leiber. 2011. Flowering catch crops used as forage plants for dairy cows: Influence on fatty acids and tocopherols in milk. Journal of Dairy Science 94:14771489.

Kälber, T., M. Kreuzer, and F. Leiber. 2013. Effect of feeding buckwheat and chicory silages on fatty acid profile and cheesemaking properties of milk from dairy cows. Journal of Dairy Research 80:81-88.

Khiaosa-Ard, R., S.F. Bryner, M.R.L. Scheeder, H.-R. Wettstein, F. Leiber, M. Kreuzer, et al. 2009. Evidence for the inhibition of the terminal step of ruminal $\alpha$-linolenic acid biohydrogenation by condensed tannins. Journal of Dairy Science 92:177-188.

Khiaosa-ard, R., C.R. Soliva, M. Kreuzer, and F. Leiber. 2011. Influence of alpine forage either employed as donor cow's feed or as incubation substrate on in vitro ruminal fatty acid biohydrogenation. Livestock Science 140:80-87.

Kronberg, S.L., E.J. Scholljegerdes, G. Barceló-Coblijn, and E.J. Murphy. 2007. Flaxseed treatments to reduce biohydrogenation of $\alpha$-linolenic acid by rumen microbes in cattle. Lipids $42: 1105$ 1111.

Larraín, R.E., D.M. Schaefer, M.P. Richards, and J.D. Reed. 2008. Finishing steers with diets based on corn, high-tannin sorghum or a mix of both: Color and lipid oxidation in beef. Meat Science 79:656-665.

Leheska, J.M., L.D. Thompson, J.C. Howe, E. Hentges, J. Boyce, J.C. Brooks, et al. 2008. Effects of conventional and grass-feeding systems on the nutrient composition of beef. Journal Animal Science 86:3575-3585.

Lourenço, M., E. Ramos-Morales, and R.J. Wallace. 2010. The role of microbes in rumen lipolysis and biohydrogenation and their manipulation. Animal 4:1008-1023.

Makkar, H.P.S. 2003. Effects and fate of tannins in ruminant animals, adaptation to tannins, and strategies to overcome detrimental effects of feeding tannin-rich feeds. Animal Feed Science and Technology 49:241-256.

Martin, S.A., and T.C. Jenkins. 2002. Factors affecting conjugated linoleic acid and trans-C18:1 fatty acid production by mixed ruminal bacteria. Journal of Animal Science 80:3347-3352.

Miller, A., E. McGrath, C. Stanton, and R. Devery. 2003. Vaccenic acid (t11-18:1) is converted to c9, t11-CLA in MCF-7 and SW480 cancer cells. Lipids 38:623-632.

Morales, R., C. Folch, S. Iraira, N. Teuber, and C.E. Realini. 2012. Nutritional quality of beef produced in Chile from different production systems. Chilean Journal of Agricultural Research 72:80-86.

Or-Rashid, M.M., T.C. Wright, and B.W. McBride. 2009. Microbial fatty acid conversion within the rumen and the subsequent utilization of these fatty acids to improve the healthfulness of ruminant food products. Applied Microbiology and Biotechnology 84:1033-1043

Patra, A.K., and J. Saxena. 2009. Dietary phytochemicals as rumen modifiers: a review of the effects on microbial populations. Antonie Van Leeuwenhoek 96:363-375. 
Patra, A.K., and J. Saxena. 2010. A new perspective on the use of plant secondary metabolites to inhibit methanogenesis in the rumen. Phytochemistry 71:1198-1222.

Patra, A.K., and J. Saxena. 2011. Exploitation of dietary tannins to improve rumen metabolism and ruminant nutrition. Journal of the Science of Food and Agriculture 91:24-37.

Petersen, M.B., and S.K. Jensen. 2014. Biohydrogenation of fatty acids is dependent on plant species and feeding regimen of dairy cows. Journal of Agricultural and Food Chemistry 62:3570-3576.

Piperova, L.S., J. Sampugna, B.B. Teter, K.F. Kalscheur, M.P. Yurawecz, Y. Ku, et al. 2002. Duodenal and milk transoctadecenoic and conjugated linoleic acid (CLA) isomers indicate that postabsorptive synthesis is the predominant source of cis-9-containing CLA in lactating dairy cows. Journal of Nutrition 132:1235-1241.

Priolo, A., and V. Vasta. 2007. Effects of tannin-containing diets on small ruminant meat quality. Italian Journal of Animal Science 6:527-530

Priolo, A., M. Bella, M. Lanza, V. Galofaroa, L. Biondia, D. Barbagalloa, et al. 2005. Carcass and meat quality of lambs fed fresh sulla (Hedysarum coronarium L.) with or without polyethylene glycol or concentrate. Small Ruminant Research 59:281-288.

Rana, M.S., A. Tyagi, S.A. Hossain, and A.K. Tyagi. 2012. Effect of tanniniferous Terminalia chebula extract on rumen biohydrogenation, $\Delta^{9}$-desaturase activity, CLA content and fatty acid composition in longissimus dorsi muscle of kids. Meat Science 90:558-563.

Shingfield, K.J., L. Bernard, C. Leroux, and Y. Chilliard. 2010. Role of trans fatty acids in the nutritional regulation of mammary lipogenesis in ruminants. Animal 4:1140-1166.

Staerfl, S.M., C.R. Soliva, F. Leiber, and M. Kreuzer. 2011. Fatty acid profile and oxidative stability of the perirenal fat of bulls fattened on grass silage and maize silage supplemented with tannins, garlic, maca and lupines. Meat Science 89:98-104.

Stringano, E., A. Gea, J-P. Salminen, and I. Mueller-Harvey. 2011. Simple solution for a complex problem: Proanthocyanidins, galloyl glucoses and ellagitannins fit on a single calibration curve in high performance-gel permeation chromatography. Journal of Chromatography A 1218:7804-7812.

Toral, P.G., G. Hervás, A. Belenguer, E. Bichi, and P. Frutos. 2013. Effect of the inclusion of quebracho tannins in a diet rich in linoleic acid on milk fatty acid composition in dairy ewes. Journal of Dairy Science 96:431-439.

Toral, P.G., G. Hervás, E. Bichi, Á. Belenguer, and P. Frutos. 2011. Tannins as feed additives to modulate ruminal biohydrogenation: Effects on animal performance, milk fatty acid composition and ruminal fermentation in dairy ewes fed a diet containing sunflower oil. Animal Feed Science and Technology 164:199-206.

Turpeinen, A.M., M. Mutanen, A. Aro, I. Salminen, S. Basu, D.L. Palmquist, et al. 2002. Bioconversion of vaccenic acid to conjugated linoleic acid in humans. The American Journal of Clinical Nutrition 76:504-510.

Vasta, V., and G. Luciano. 2011. The effects of dietary consumption of plants secondary compounds on small ruminants' products quality. Small Ruminant Research 101:150-159.
Vasta, V., H.P.S. Makkar, M. Mele, and A. Priolo. 2009a. Ruminal biohydrogenation as affected by tannins in vitro. British Journal of Nutrition 102:82-92.

Vasta, V., M. Mele, A. Serra, M. Scerra, G. Luciano, M. Lanza, et al. 2009b. Metabolic fate of fatty acids involved in ruminal biohydrogenation in sheep fed concentrate or herbage with or without tannins. Journal of Animal Science 87:2674-2684.

Vasta, V., P. Pennisi, M. Lanza, D. Barbagallo, M. Bella, and A. Priolo. 2007. Intramuscular fatty acid composition of lambs given a tanniniferous diet with or without polyethylene glycol supplementation. Meat Science 76:739-745

Vasta, V., A. Priolo, M. Scerra, K.G. Hallett, J.D. Wood, and O. Doran. 2009c. $\Delta^{9}$ Desaturase protein expression and fatty acid composition of longissimus dorsi muscle in lambs fed green herbage or concentrate with or without added tannins. Meat Science 82:357-362

Vasta, V., D.R. Yáñez-Ruiz, M. Mele, A. Serra, G. Luciano, M. Lanza, et al. 2010. Bacterial and protozoal communities and fatty acid profile in the rumen of sheep fed a diet containing added tannins. Applied and Environmental Microbiology 76:2549-2555.

Waghorn, G.C. 2008. Beneficial and detrimental effects of dietary condensed tannins for sustainable sheep and goat productionProgress and challenges. Animal Feed Science and Technology 147:116-139.

Waghorn, G.C., G.B. Douglas, J.H. Niezen, W.C. McNabb, and A.G Foote. 1998. Forages with condensed tannins - their management and nutritive value for ruminants. Proceedings of the New Zealand Grassland Association 60:89-98.

Waghorn, G.C., and W.C. McNabb. 2003. Consequences of plant phenolic compounds for productivity and health of ruminants. Proceedings of the Nutrition Society 62:383-392.

Wallace, R.J., N. McKain, K.J. Shingfield, and E. Devillard. 2007. Isomers of conjugated linoleic acids are synthesized via different mechanisms in ruminal digesta and bacteria. Journal of Lipid Research 48:2247-2254.

Whitney, T.R., C.J. Lupton, and S.B. Smith. 2011. Redberry juniper as a roughage source in lamb feedlot rations: Wool and carcass characteristics, meat fatty acid profiles, and sensory panel traits. Meat Science 89:160-165

Whitney, T.R., and S.B. Smith. 2015. Substituting redberry juniper for oat hay in lamb feedlot diets: Carcass characteristics, adipose tissue fatty acid composition, and sensory panel traits. Meat Science 104:1-7.

Willems, H., M. Kreuzer, and F. Leiber. 2014. Alpha-linolenic and linoleic acid in meat and adipose tissue of grazing lambs differ among alpine pasture types with contrasting plant species and phenolic compound composition. Small Ruminant Research 116:153-164

Yu,Z., and R.J.Forster. 2005. Nucleic acid extraction, oligonucleotide probes and PCR methods. p. 81-104. In Makkar, H.P.S., and C.S. McSweeney (eds.) Methods in gut microbial ecology for ruminants. Springer, Dordrecht, The Netherlands. 